\title{
El género como factor condicionante de la victimización y de la criminalidad femenina
}

\author{
María Acale Sánchez \\ Universidad de Cádiz, Departamento de Derecho Internacional Público, Penal y Procesal \\ maria.acale@uca.es
}

\section{Resumen}

En este trabajo, se analiza la relación que existe entre género, victimización, criminalidad, ejecución de la pena de prisión y reinserción social de la mujer delincuente. Son los frutos del trabajo realizado en el seno del proyecto I+D Igualdad y Derecho penal: El género y la nacionalidad como criterios primarios de discriminación (I+D 2010-19781). Se ha llegado a las conclusiones que se pondrán de manifiesto aquí a través de métodos empleados generalmente en criminología, como son las encuestas (que, a la vez, eran de victimización y de criminalidad) y los foros de discusión llevados a cabo en una serie de prisiones españolas y en otra salvadoreña. Asimismo, se ha recurrido al estudio de los datos que ofrece la estadística oficial y la jurisprudencia. Todas estas fuentes de información han venido a concluir que el género es un factor que pauta la vida de las mujeres víctimas de delito, que incide en su carrera criminal y que, posteriormente, se convierte en un factor decisivo durante la ejecución de la pena. Podemos pedirles legítimamente que eliminen la violencia de sus vidas, pero solo si nosotros somos capaces de eliminar la violencia de género que la sociedad tolera que soporten ellas. De no ser así, sus acciones delictivas no son más que una forma de equivocada e inconsciente autodefensa.

Palabras clave: igualdad; discriminación; penología; delito; cárcel; pena.

\begin{abstract}
Gender as a Restraining Factor of Victimization and Female Criminality
This paper analyzes the relationship between gender, victimization, criminality, imprisonment and the social reintegration of women offenders based on the results of research carried out in the framework of the project Equality and Law: Gender and Nationality as Primary Factors of Discrimination (I+D 2010-19781). Criminological research methods were used, including surveys on victimization and crime and discussion forums carried out in Spanish prisons and one from El Salvador, as well as data from official statistics and case law. The findings show that gender is a factor that rules the lives of women victims of crime, influences their criminal career and subsequently becomes a decisive factor in the execution of the sentence. Women can legitimately be asked to eliminate violence from their lives, but only if we are able to eliminate the gender violence against women tolerated by society. Otherwise, their criminal actions are only a form of mistaken and unconscious self-defense.
\end{abstract}

Keywords: equality; discrimination; penology; crime; prison; prison sentence 


\section{Sumario}

1. Introducción

2. La vinculación existente entre victimización y criminalidad

3. Criminalidad femenina
4. El tratamiento penitenciario de género

5. Victimización secundaria

6. Conclusiones

Referencias bibliográficas

\section{Introducción}

La privación de libertad de las mujeres plantea una serie de problemas comunes que se repiten en países muy distintos. Así lo ha entendido Naciones Unidas, que, tras aprobar las reglas mínimas para el tratamiento de los reclusos, a la vista además del aumento del número de mujeres privadas de libertad, mediante la Resolución de la Asamblea General de 16 de marzo de 2011, aprobó las Reglas de las Naciones Unidas para el tratamiento de las reclusas y medidas no privativas de libertad para las mujeres delincuentes, más conocidas como Reglas de Bangkok. En ellas, se intenta prestar atención a las especificidades que, por razón de género, lleva aparejada la ejecución de la pena privativa de libertad para las mujeres.

A pesar del esfuerzo de Naciones Unidas por visibilizar la situación que viven las mujeres en prisión, no se puede desconocer que el respeto de los derechos de las personas que están privadas de libertad depende del dato previo del respeto de los derechos humanos de la sociedad en su conjunto. De ahí que sea tan complejo comparar siquiera idealmente la forma de cumplimiento de pena privativa de libertad en países como España, Túnez, Cuba, México, El Salvador, Estados Unidos o Turquía, porque se trata de países que no garantizan de la misma forma el disfrute de los derechos humanos de la población en su conjunto.

Tras la aprobación de este segundo grupo de reglas penitenciarias, el 21 de agosto de 2013 la Asamblea General presentó un diagnóstico sobre las condiciones de cumplimiento de la pena privativa de libertad en el mundo en el informe realizado por la relatora especial titulado Causas, condiciones y consecuencias de la encarcelación para las mujeres. De su lectura, puede concluirse la especial situación de vulnerabilidad que sufren las mujeres que soportan un daño mucho mayor que el que ellas mismas han causado con la comisión de su delito a sus víctimas concretas y a la sociedad. En particular, afirma:

[...] la estigmatización, el alejamiento social y los sentimientos de vergüenza y culpa también pueden contribuir a obstaculizar la reinserción. El estigma y la pérdida de determinados derechos son un impedimento para restablecer las relaciones y los vínculos sociales. El apoyo familiar y comunitario es fundamental para lograr la reinserción y también para reducir las posibilidades de reincidencia ${ }^{1}$.

1. Naciones Unidas (2013), Causas, condiciones y consecuencias de la encarcelación para las mujeres [en línea], <http://www.un.org/es/globalissues/women/>, 21 de agosto, p. 22 [Consulta: 20 julio 2014]. 
A pesar de esas amplias diferencias de partida entre el disfrute de los derechos humanos en todos esos países, actualmente los estereotipos de género siguen pautando la vida de las mujeres, la cuales están sometidas a procesos concretos de victimización, como son todos aquellos relacionados con la violencia de género en sentido amplio; la de las mujeres delincuentes, a las que se priva de libertad, apartándolas además de la sociedad, de su familia, de cuyo cuidado se han encargado por razón de género y la de las exdelincuentes, sobre las que recae con más fuerza el estigma carcelario.

Por lo que a España se refiere, las estadísticas oficiales ponen de manifiesto que, aunque es uno de los países más seguros de la Unión Europea, tiene la tasa de encarcelamientos más elevada también de la Unión, lo que determina que sea el que posee la tasa más elevada de mujeres en prisión ${ }^{2}$. Esta sobrepoblación penitenciaria masculina y femenina no se debe a que España sea un país especialmente "violento», a la vista del bajo número de deiltos cometidos, sino que es fruto del Código Penal vigente, que, durante las últimas reformas, ha tendido a ampliar las conductas castigadas con penas de prisión, a alargar su duración y a incorporar mecanismos que impidan el disfrute de regímenes peniteniciarios abiertos.

Si se contrastan ambos datos — tasa baja de criminalidad y número elevado de personas privadas de libertad-, puede concluirse con facilidad que la prisionización del Código Penal español no se corresponde con la sociedad que la soporta, lo que equivale a afirmar que se trata de una dureza penal gratuita e innecesaria. Basta constatar que países más inseguros y con tasas de criminalidad superiores a la española mantienen un volumen de población penitenciaria inferior.

Ello determina que la sociedad no solo genera una clase concreta de delincuencia, sino que la crea al definir legalmente qué conductas son constitutivas de delito y con qué sanciones van a ser castigadas. La criminalidad masculina y femenina no puede analizarse si no se parte, en definitiva, de esta artificialidad inicial.

\section{La vinculación existente entre victimización y criminalidad}

La mujer delincuente soporta un iter discriminatorio particular a través de un hilo que une los procesos de victimización primaria, de criminalización y de victimización secundaria en prisión. En esta línea, muchas de las mujeres que están privadas de libertad, han sufrido o están sufriendo violencia por el hecho de estar en manos de un hombre (su marido, su compañero sentimental o el que trafica con su cuerpo). A esto se refiere la regla 44 de Naciones Unidas, en virtud de la cual se parte objetivamente de que «el número de reclusas que han sido víctimas de violencia en el hogar es desproporcionado", a lo que ha de

2. Véase «España es el país de Europa con mayor tasa de mujeres en prisión», 20 Minutos [en línea], <http://20minutos.es/noticia/2057658/0/mujeres/prision/españa> (28 de abril de 2014). 
unírsele el «fuerte vínculo entre la violencia contra la mujer y la encarcelación de las mujeres, ya sea antes, durante o después de la encarcelación». En esa misma línea inciden las estadísticas del Ministerio del Interior español ${ }^{3}$, que ponen de manifiesto cualitativamente que muchas mujeres condenadas han sido previamente objeto de vejaciones, insultos, amenazas, mal trato, sometimiento forzado al ejercicio de la prostitución o a la mendicidad, en definitiva, a conductas constitutivas de delito, y parece que existe una relación entre esa victimización previa y la posterior comisión de delito.

Los casos más extremos y a la vez más claros son aquellos en los que, por «amor» o por "presiones» de su marido o de su hijo, arriesgan su libertad, al intentar hacerles llegar droga dentro del establecimiento penitenciario; se hacen responsables ante la policía de la droga incautada en su domicilio, a fin de proteger a los miembros de su familia, de los que se sienten protectoras por su papel de madres, de esposas o incluso de abuelas, o deciden obtener ingresos a través de actividades delictivas en los casos de mujeres que delinquen por carecer de expectativas laborales. Pero tampoco pueden dejarse de lado los supuestos en los que son condenadas por delitos que no han cometido de forma individual, sino como coautoras o partícipes del que ha cometido un hombre que lleva la voz cantante también en su vida privada ${ }^{4}$. Con todo, tampoco es extraño encontrar el caso de mujeres que, sin llegar al extremo de haber sido «víctimas» de un delito, han sido sin duda alguna «objetos instrumentales a manos de un hombre del que dependen" y que se ha lucrado de ellas. En este sentido, es interesante resaltar que la llegada de las primeras delincuentes de cuello blanco a prisión se ha producido tras fracasar por parte de sus defensas una especie de teoría «del amor» que viene a poner en valor el hecho de que una mujer "enamorada» es una mujer que no pone en duda las operaciones financieras de su marido 5 . Es cierto que se ha mantenido expresamente que esta supuesta teoría es aplicable también a los hombres enamorados que confían la gestión de los caudales a sus esposas, pero no puede dejarse de subrayar el dato de que, hasta este momento, ninguna defensa letrada de un hombre acusado de blanqueo de capitales ha alegado confianza hacia la gestión de sus esposas, entre otros motivos porque difícilmente este razonamiento puede pasar a ser de mera hipótesis hipócrita que pretende justificar lo que, en el fondo, no es más que un razonamiento machista (esta ha sido la vía de defensa seguida en la pieza separada del Caso Malaya, y que terminó condenando a dos conocidas mujeres del mundo de la prensa del corazón a penas de prisión por delito de

3. http://www.mir.es.

4. Puede verse el Diario de Cádiz de 29 de enero de 2011, en el que se hacen públicos los primeros resultados obtenidos por Instituciones Penitenciarias al respecto: «el $80 \%$ de las más de 5.700 reclusas que hay en España han sufrido abuso en sus parejas, lo que puede estar detrás de su conducta delictiva».

5. La noticia ha sido seguida por todos los medios de comunicación. Léase, por ejemplo, Reinformación Balear (<http://www.periodistadigital.com/reinformacionbalear/mallorca/2014/02/09/la-infanta-le-ha-dado-a-castro-todo-un-real-reves-contra-la-teoria-del-amorpoco-se-puede-hacer.shtml> [Consulta: 28 julio]). 
blanqueo de capitales del dinero proveniente de las actividades ilícitas de sus parejas: véase la Sentencia del Tribunal Supremo de 9 de junio de 2014).

En 2011, se reconoció en nuestro país por primera vez de forma oficial esta vinculación, con la puesta en marcha del programa de tratamiento para mujeres privadas de libertad "Ser mujer.eS ${ }^{6}$. Su objetivo no era otro que empoderar a las reclusas en su condición de mujeres, en su dignidad personal y en el rechazo a la violencia de género, como forma de discriminación femenina. Así, Instituciones Penitenciarias reconocía la existencia de muchas mujeres privadas de libertad que habían sufrido violencia por el hecho de estar a manos de su marido o de su compañero sentimental, si bien no estableció relación alguna entre el proceso de victimización y el delito cometido por ellas. Un poco más allá, llegó posteriormente el Programa de acciones para la igualdad entre mujeres y hombres en el ámbito penitenciario en 2010, en desarrollo de la Ley Orgánica 3/2007, para la igualdad efectiva de mujeres y hombres, en el que, con claridad afirmaba:

[...] hoy sabemos de la altísima frecuencia que jalonan el historial de las mujeres encarceladas los episodios de abusos sexuales y maltrato familiar y de pareja; y la relación directa que estas experiencias han tenido en su historial delictivo y las consecuentes secuelas físicas y psicológicas que acarrean ${ }^{7}$.

Constatado el dato, puede afirmarse que los procesos de violencia de género que sufren estas mujeres están detrás de los delitos que han cometido o por lo menos es una variable que no puede ignorarse, ni tampoco ocultarse. En este sentido, no se desconoce que, en estos procesos victimales y criminales, el género es el motor que los propicia. Se cierra así el círculo de la violencia de género, que empuja a muchas mujeres a moverse en el ámbito criminal. Esto no siginfica defender que detrás de una mujer autora de delito hay una víctima de un delito cometido por un hombre sobre ella por el mero hecho de ser mujer, porque se estaría haciendo una lectura completamente victimista de la criminalidad femenina desde un punto de vista del género (Mestre, 2005: 217), pero sí pone de manifiesto que, cuando coinciden, una y otra son causa y consecuencia a través de una relación de causalidad desde el punto de vista de los estereotipos de género entre victimización primaria y criminalidad y victimización secundaria, que, aunque ni determina que todas las mujeres que han sufrido violencia de género son autoras de delito, ni que todas las mujeres que han cometido delito han sido a su vez víctimas de violencia a manos de un hombre, permite observar que hay casos en los que sí se establece esa vinculación.

6. Secretaría General de Instituciones Penitenciarias, Programa de prevención de violencia de género para las mujeres en los centros penitenciarios [en línea], Documentos Penitenciarios <www.060.es>.

7. Secretaria General de Instituciones Penitenciarias, Programa de acciones para la igualdad entre mujeres y hombres en el ámbito penitenciario [en línea], p. 11, <http://www. institucionpenitenciaria.es/web/export/sites/default/datos/descargables/publicaciones/Programa_para_la_igualdad_accesible.pdf >. 
Con lo cual, las políticas que inciden en la prevención de la victimizacion inciden también en la prevención de la criminaidad femenina (o de una de sus formas). Y, en este sentido, poco contribuye a prevenir la criminalidad decisiones políticas que dificultan la detección de la violencia de género o tienden sencillamente a trivializarla, al mostrarla como un fenómeno normalizado, como en algunos casos puede estar produciéndose en prisión. A ellos se hará referencia posteriormente.

\section{Criminalidad femenina}

\subsection{Acercamiento}

Hoy, la criminalidad femenina no puede entenderse ni tampoco explicarse si no es desde una perspectiva sociológica, en la que su entidad y sus características dependen del marco que la produce, más allá de aspectos individuales como la agresividad, la violencia o la inseguridad personal, que no definen con carácter general a las mujeres - ni a los hombres-. Por tanto, su prevención exige la puesta en marcha de programas sociales dirigidos al conjunto, más que a personas individuales, a las cuales habrá que prestar atención desde un punto de vista preventivo especial una vez cometido el delito y comenzada la ejecución de la pena correspondiente.

Y aún así, los datos que arrojan las estadísticas siguen poniendo de manifiesto que, como hace dos siglos, las mujeres delinquen en números y términos muy inferiores a lo que lo hacen los hombres. Eso sí, el aumento que ha sufrido durante los últimos veinte años la criminalidad femenina es muy superior al aumento de la criminalidad masculina (Almeda, 2007: 25 y s.). Los factores que explican los motivos por los cuales las mujeres delinquen más que antes pero aún mucho menos que los hombres parece que están relacionados con el incremento del papel femenino en la sociedad y en la familia, que ha pasado de ser un miembro protegido a ser un sujeto superprotector, que ocupa ya muchas veces el papel de "cabeza» de familia que tradicionalmente ha desempeñado el hombre. Y, a la vista de los problemas económicos que arrastra, debidos en parte a su falta de preparación profesional, lo que las obliga a trabajar en los sectores menos reconocidos socialmente, peor remunerados y de los que en época de crisis es más fácil prescindir, el empleo femenino deba ligarse a la feminización de la pobreza y, de su mano, al nacimiento de unas formas de criminalidad consustanciales a ella. Y con esa criminalidad es con la que se ceba el Derecho Penal y la que acaba con sus huesos en prisión (Bodelón, 2007: 42).

El análisis de los datos estadísticos que proporciona el Ministerio del Interior sobre los delitos cometidos durante estos últimos años, así como los facilitados por la Secretaría de Estado de Instituciones Penitenciarias sobre la población penitenciara correspondiente a esos mismos años, pone de manifiesto la escasa incidencia de la delincuencia femenina en las cifras globales sobre criminalidad y su correlativa escasa presencia en las prisiones españolas, y a la vez la enorme incidencia de la nacionalidad — para hombres y mujeres - en 
esas mismas fuentes. De ahí también que la doctrina científica haya prestado escaso interés al tema de la delincuencia femenina y, cuando lo ha hecho, en muchos casos, la interprete en clave masculina (Larrauri, 1994: 1; Acale, 2006: 44): más escaso es aún el interés que ha despertado la delincuencia de mujeres extranjeras en términos macrocriminales, en atención a los números totales que se desprenden de las estadísticas, aunque en términos microcriminales cada uno de esos casos es muy interesante por su altísima representación. Solo se ha tenido en cuenta, por ejemplo, en algunos estudios, las condenadas por delitos de tráfico de drogas, pero nada más.

Por otra parte, no puede dejarse de lado la escasez de datos de interés incluidos dentro de las estadísticas penitenciarias, lo que empobrece mucho cualquier estudio realizado sobre ellas. En este sentido, para llegar a conocer a la población penitenciaria de las cárceles españolas, sería muy importante que, en un futuro, se estudiaran más variables y que, además, se hicieran públicos los resultados disgregados en atención al sexo de las personas privadas de libertad, cumpliendo así la obligación establecida por la Ley Orgánica 7/2007, de 22 de marzo, para la igualdad efectiva de mujeres y hombres, en cuyo artículo 20, obliga a los poderes públicos a «incluir sistemáticamente la variable de sexo en las estadísticas, encuestas y recogida de datos que lleven a cabo».

\subsection{Análisis macropenitenciario y micropenitenciario}

\subsubsection{La estadistica penitenciaria}

Si se analizan los datos del Ministerio del Interior sobre personas privadas de libertad en las cárceles españolas a 31 de diciembre de 2015 y se atiende a los delitos concretos que dan lugar a la privación de libertad de las mujeres, se podrá comprobar que el primer puesto lo ocupan los delitos contra la salud pública (tráfico de drogas), seguidos de los delitos contra el patrimonio y el orden socioeconómico, el homicidio y sus formas y lesiones. El resto se distribuye en otras cantidades menos relevantes (sobre los datos a 31 de diciembre de 2010, véase Acale, 2011: 17).

Se trata de delitos que están castigados con penas privativas de libertad elevadas, lo que hace que estas mujeres estén en prisión durante un periodo largo de tiempo (Acale, 2002: 108 y s.).

El dato cuantitativo permite realizar una serie de valoraciones al respecto de la incidencia del género en la concreta criminalidad femenina. Así, a la vista de los dos grupos de figuras que determinan el mayor número de penas privativas de libertad, puede afirmarse que la criminalidad femenina se caracteriza porque está dirigida a la finalidad de conseguir dinero, ya sea para hacer frente a sus necesidades derivadas de su dependencia de las mismas drogas con las que trafican a pequeña escala ${ }^{8}$, ya sea para hacer frente a la pobreza en la que viven ellas y los miembros de su familia que están a su cargo. Se trata, pues, de una delincuencia funcional en todo caso a sus carencias o a sus necesidades

8. Véanse las sentencias analizadas en el epígrafe siguiente. 
Tabla 1. Tipologías de delitos por los que las mujeres están privadas de libertad

\begin{tabular}{lr}
\hline Tráfico de drogas & 1.552 \\
Contra el patrimonio & 1.383 \\
Homicidios & 298 \\
Lesiones & 188 \\
Resto & 575 \\
Total & 3.996 \\
\hline
\end{tabular}

Fuente: elaboración propia a partir de datos del Ministerio del Interior.

económicas; de ahí también los problemas específicos de salud que han de padecer (por ejemplo: VIH) (Igareda, 2007: 96).

Las mujeres, en efecto, son utilizadas por las organizaciones criminales para introducir la droga en España, en pequeñas cantidades en su propio cuerpo — las llamadas «mulas» (véase la descripción del proceso de ingestión, viaje y llevada a España en Dorado, 2005: 317 y s.; véase también Bodelón, 2007: 113)—. En particular, el tráfico de drogas a pequeña escala es un delito que no requiere de especial destreza, ni supone un riesgo personal para su autor o su autora, por lo que su consumación queda en manos muchas veces del azar, de la suerte, en definitiva, de que la actividad delictiva sea o no detectada por las fuerzas policiales. Estos motivos parecen hacer que las mujeres se decanten por la comisión de los mismos (ya sean o no consumidoras de estas sustancias).

La estadística no deja confirmar, pero sí permite atisbar, que la mayor parte de las veces se tratará de delitos cometidos de forma individual, más que en coautoría, y ello a pesar de que, como se decía, en muchos casos, las mujeres no van a ser más que el último eslabón de la cadena de la organización criminal (Naredo, 2005: 292), en la que no se integran sino para la que simplemente trabajan y, caso de ser descubiertas, preferirán no delatar al resto de sus miembros, de forma que la organización contraiga con ellas una «deuda» que esperan que salden en algún momento, por ejemplo: volviéndoles a encargar «trabajos» una vez que recuperen la libertad, siendo entonces cuando se produce su incorporación a la programación de las actividades de la organización. Esto es lo que determina que, aunque el Código Penal prevea una disminución de la pena en caso de colaboración con la Administración de Justicia (art. 376 del Código Penal), muchas víctimas no puedan beneficiarse de ella, pues prefieren «proteger» a la organización, por miedo o por «solidaridad».

En este sentido, si se tiene en consideración que la población penitenciaria femenina extranjera se concentra en las prisiones de Andalucía y Madrid, y se constata a la vez que la gran mayoría de estas mujeres han intentado entrar en España hachís y cocaína a través del estrecho de Gibraltar o del Aeropuerto Adolfo Suárez Madríd Barajas, respectivamente, se pone de manifiesto un dato relevante, y es que muchas de estas mujeres extranjeras no residían en España antes de cometer su delito, por lo que no eran «inmigrantes» y carecían de «domicilio» en nuestro país (Aguilera, 2005: 293; Boza, 2015: 261). 
Por otra parte, desde una perspectiva de género, es también fácil entender que muchas mujeres, con la finalidad de "proteger» a otros miembros de su familia (maridos, hijos, hijas, padres, madres), prefieren guardar silencio y no delatarles y, tras la práctica de un registro policial, por ejemplo, llegan a responsabilizarse de un delito que no han cometido por un tercero, que, en la mayoría de los casos, tendrá un antecedente penal y verá su pena agravada en sentencia al apreciarle la circunstancia de reincidencia, mientras que estas mujeres «ajenas» al mundo de la criminalidad, por definición, carecen de antecedentes penales y obtendrán una condena inferior.

Respecto al segundo grupo de figuras delictivas - los delitos contra el patrimonio-, las estadísticas oficiales no distinguen dentro de ellos cuáles son las modalidades concretas cometidas por mujeres ni por hombres: hurtos, robo con fuerza en las cosas, robo con violencia o intimidación en las personas, estafas, apropiaciones indebidas, etc. El dato es relevante, en la medida en que, si se observa, dentro de este listado, se incluyen figuras como el hurto, la estafa o la apropiación indebida que no requieren el empleo de violencia, intimidación o fuerza, sino que más bien requieren de su astucia, frente a los delitos de robo - con fuerza en las cosas o con violencia o intimidación en las personas-, en los que sí se requiere que se corra una cierta dosis de riesgo, pues ha de estar en condiciones de hacer frente a la eventual resistencia física que pueda presentar la víctima o un tercero que salga en su auxilio.

A falta del dato estadístico, habrá que recurrirse a la jurisprudencia para comprobar el dato cualitativo sobre el número de mujeres condenadas por robos violentos o por robos con fuerza en las cosas, así como para analizar en estos casos si la mujer actúa sola (esto es, si se trata de supuestos de autoría individual) o si, por el contrario, lo hace acompañada (como coautora con otra persona - hombre o mujer-), así como la incidencia que haya podido tener en su actuación el síndrome de abstinencia que, a simple vista, parece que envalentona a quien lo sufre (la incidencia del consumo de drogas en hombres y mujeres se constata cuando se analizan los delitos cometidos por ambos, por lo que, en todo caso, se estará ante una forma de delincuencia funcional).

Además, se trata de delitos que están castigados con penas privativas de libertad elevadas, lo que hace que todas estas personas estén en prisión durante un periodo largo de tiempo. La reforma operada del delito de tráfico de drogas por la LO 5/2010 vino a paliar en parte estas cifras, en la medida en que ha incorporado una atenuación facultativa de la pena en el nuevo párrafo segundo del artículo 368, que establece «no obstante lo dispuesto en el párrafo anterior, los Tribunales podrán imponer la pena inferior en grado a las señaladas en atención a la escasa entidad del hecho y a las circunstancias personales del culpable»?.

9. Ya en el Programa de acciones para la igualdad entre mujeres y hombres en el ámbito penitenciario, p. 45, se señalaba que una de las líneas de trabajo a seguir era la de «impulsar el debate para disminuir la penalización de las conductas de tráfico de drogas cuando se trata de supervivencia económica, y de personas que asumen un papel secundario en la organización criminal». 
Tabla 2. Tipologías de delitos por los que los hombres están privados de libertad

\begin{tabular}{lr}
\hline Contra el patrimonio & 18.803 \\
Salud pública & 10.361 \\
Violencia de género & 3.841 \\
Homicidios & 3.594 \\
Contra la libertad sexual & 3.050 \\
Resto & 8.790 \\
Total & 48.449 \\
\hline
\end{tabular}

Fuente: elaboración propia a partir de datos del Ministerio del Interior.

La distribución por parcelas cambia cuando se trata de hombres

En el caso de los hombres, se aprecia que los delitos contra el patrimonio pasan a ocupar el primer lugar al listar sus preferencias delictivas y a pesar de que no se señale tampoco, expresamente en este caso, a qué clase de delitos se está haciendo referencia, no existen dudas de que incluyen tanto los delitos patrimoniales violentos como los no violentos. En este caso, el tráfico de drogas pasa a ocupar el segundo puesto, de forma que, si se compara con los delitos que dan lugar a la privación de libertad de las mujeres, se produce un cambio en cuanto a las preferencias delictivas.

A partir de este lugar, llama la atención la aparición con nombre propio de los condenados por delitos relacionados con la violencia de género, que representan, a día de hoy, el 7,6\% de la población penitenciaria masculina. En este caso, no puede pasar desapercibido que se trata de personas que entran en la prisión la mayoría de las veces por delitos que están castigados con una pena privativa de libertad de corta duración, lo que da lugar a un gran movimiento de penados que entran y salen del establecimiento, impidiendo que se lleve a cabo un programa de tratamiento "completo" y dificultando además el tratamiento de los penados que llevan más tiempo en prisión y que tienen pendientes condenas más largas que cumplir.

Con nombre propio, después de los homicidios, aparecen los delitos contra la libertad sexual, respecto de los cuales hay un número residual de 54 mujeres privadas de libertad, sin que de las estadísticas se deduzca si fueron condenadas como autoras únicas, si actuaron en coautoría con un hombre o si se trató de mujeres que atentaron contra la libertad sexual de un menor, de un incapaz o de una persona con pleno goce de sus facultades mentales.

La comparación de los delitos que dan lugar al internamiento en prisión de hombres y mujeres pone de manifiesto, pues, que el género impone un orden de preferencias.

Según datos de Instituciones Penitenciarias, la población reclusa durante los últimos años ha disminuido.

Hay que tener en consideración que esta disminución de personas en prisión coincide, además, con la disminución del número de delitos cometidos según los datos policiales que ofrece el Ministerio del Interior. Esta disminución se debe a dos modificaciones del Código Penal que han tenido su 
Tabla 3. Distribución por sexo de la población penitenciaria

\begin{tabular}{lccccccc}
\hline & 2009 & 2010 & 2011 & 2012 & 2013 & 2014 & 2015 \\
\hline Hombres & 70.003 & 68.141 & 65.184 & 63.372 & 61.682 & 60.040 & 48.838 \\
& $(92,01 \%)$ & $(92,17 \%)$ & $(92,5 \%)$ & $(92,38 \%)$ & $(92,39 \%)$ & $(92,35 \%)$ & $(92,16 \%)$ \\
\hline Mujeres & 6.076 & 5.788 & 5.288 & 5.225 & 5.083 & 4.977 & 4.153 \\
& $(7,99 \%)$ & $(7,83 \%)$ & $(7,5 \%)$ & $(7,62 \%)$ & $(7,61 \%)$ & $(7,65 \%)$ & $(7,84 \%)$ \\
\hline Total & 76.079 & 73.929 & 70.472 & 68.597 & 66.765 & 65.017 & 52.991 \\
\hline
\end{tabular}

Fuente: elaboración propia a partir de datos del Ministerio del Interior.

repercusión inmediata en la población penitenciaria. La primera de ellas es la inclusión dentro del artículo 368 de una cláusula en la que se señala que «los tribunales podrán imponer la pena inferior en grado a las señaladas en atención a la escasa entidad del hecho y a las circunstancias personales del culpable», previsión que está siendo muy útil para paliar —a la vista de los datos penitenciarios - las largas condenas a que da lugar la aplicación rigurosa del artículo 368. También ha influido la reforma del artículo 36.2, del que se ha eliminado el automatismo con el que, desde que fue incorporado al Código en 2003, se ha venido aplicando el periodo de seguridad, en virtud del cual las personas condenadas a penas privativas de libertad superiores a 5 años no podrían ser clasificadas en tercer grado de tratamiento penitenciario hasta que hubieran cumplido la mitad de la condena impuesta. Esto determina que, tras la reforma mencionada, la imposición de una pena de prisión de 5 años no tiene por qué dar lugar al internamiento en prisión por tiempo mínimo de

Gráfico 1. Disminución de la población penitenciaria

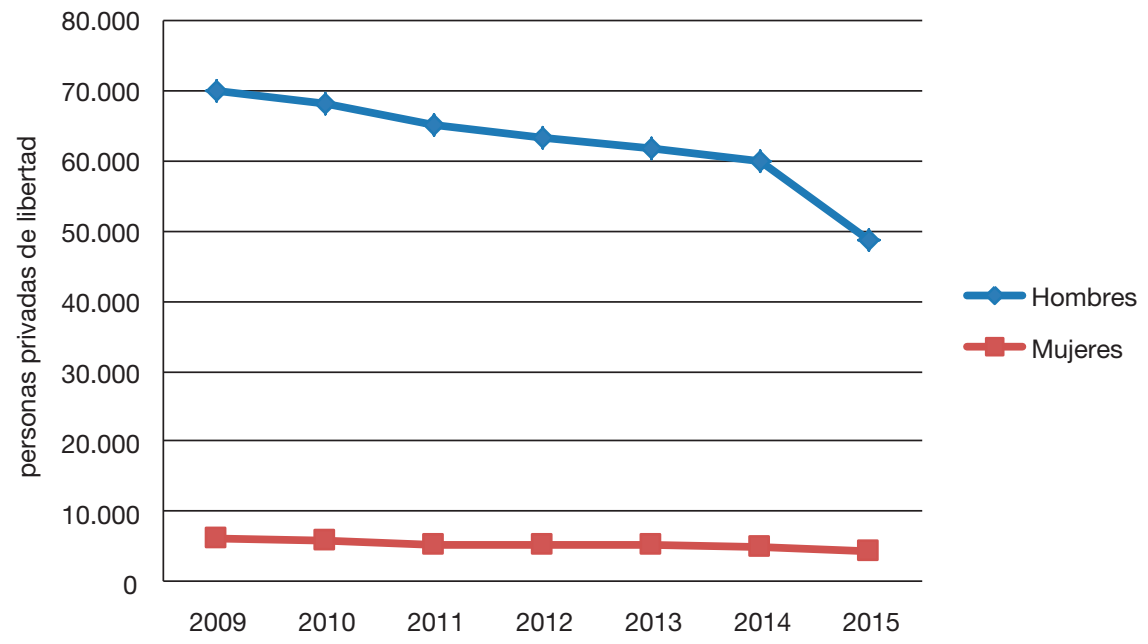

Fuente: elaboración propia a partir de datos del Ministerio del Interior. 
Tabla 4. Población penada reclusa por grupos de edad, según sexo

\begin{tabular}{|c|c|c|c|c|c|c|c|c|c|c|c|c|c|c|}
\hline \multirow[b]{2}{*}{ Edad } & \multicolumn{2}{|c|}{2009} & \multicolumn{2}{|c|}{2010} & \multicolumn{2}{|c|}{2011} & \multicolumn{2}{|c|}{2012} & \multicolumn{2}{|c|}{2013} & \multicolumn{2}{|c|}{2014} & \multicolumn{2}{|c|}{2015} \\
\hline & $\mathrm{H}$ & $M$ & $\mathrm{H}$ & $M$ & $\mathrm{H}$ & $M$ & $\mathrm{H}$ & $M$ & $\mathrm{H}$ & $M$ & $\mathrm{H}$ & $M$ & $\mathrm{H}$ & $M$ \\
\hline 18 a 20 & 615 & 40 & 651 & 24 & 581 & 25 & 510 & 29 & 449 & 32 & 347 & 14 & 305 & 12 \\
\hline 21 a 25 & 6.654 & 550 & 6.623 & 467 & 6.625 & 424 & 5.372 & 368 & 5.163 & 346 & 4.703 & 343 & 4.187 & 281 \\
\hline 26 a 30 & 11.322 & 984 & 11.206 & 933 & 10.339 & 843 & 8.305 & 676 & 8.120 & 637 & 7.922 & 592 & 7.383 & 571 \\
\hline 31 a 40 & 19.189 & 1.576 & 19.214 & 1.520 & 18.414 & 1.372 & 18.108 & 1.386 & 17.933 & 1.467 & 17.383 & 1.446 & 16.455 & 1.401 \\
\hline 41 a 60 & 15.737 & 1.379 & 15.711 & 1.409 & 15.761 & 1.300 & 18.009 & 1.547 & 18.569 & 1.560 & 18.758 & 1.609 & 18.518 & 1.605 \\
\hline+60 & 1.378 & 94 & 1.388 & 105 & 1.651 & 105 & 1.622 & 113 & 1.704 & 118 & 1.880 & 111 & 1.852 & 136 \\
\hline NC & & & & & & & 52 & 9 & 5 & 0 & 5 & 1 & 5 & 0 \\
\hline
\end{tabular}

Fuente: elaboración propia a partir de datos del Ministerio del Interior.

dos años y seis meses, sino que, una vez que se alcance la clasificación en tercer grado y se cumplan los requisitos para acceder a la libertad condicional, podrá adelantarse la excarcelación a los tres años y medio (esto es, una vez cumplidas las tres cuartas partes de la condena) ${ }^{10}$.

Es decir, en un marco penológico más benévolo, se han reducido las infracciones penales detectadas, sin que se pueda afirmar ya que, durante estos últimos años de la crisis, se haya aumentado "demasiado» el número de efectivos policiales dedicados a la lucha contra el delito, que, a pesar de no haber sufrido — estar sufriendo- la tasa de reposición del 10\% que el Real Decreto Ley 20/2011, de 30 de diciembre, de medidas urgentes en materia presupuestaria, tributaria y financiera para la corrección del déficit público, ha crecido menos que durante los años anteriores. Por tanto, quizás esto pueda llevar a afirmar que, sencillamente, ha disminuido la delincuencia (de personas nacionales y extranjeras en situación administrativa regular o no), en un contexto nada propicio para ello, con la incidencia del desempleo en las familias españolas.

En cualquier caso, es muy llamativo el paulatino descenso de la criminalidad masculina frente al mantenimiento de la femenina. En cierta medida, puede pensarse que los delitos cometidos por mujeres no bajan en el mismo número que lo hacen los cometidos por hombres, porque las razones que determinan una y otra clase de criminalidad son distintas. En este sentido, la lectura de este dato puede justificarse diciendo que la criminalidad femenina, aunque sea escasa, obedece a causas estructurales que permanecen en el tiempo, mientras que las razones que justifican la criminalidad masculina no son «estructurales» a esa condición masculina y depende de otros factores más fácilmente motivables $y$, por ende, controlables.

10. En este sentido, ha de resaltarse que, a pesar de la transformación tan dura que ha sufrido la libertad condicional tras la reforma operada por la LO 1/2015, se ha incluido un nuevo mecanismo en el artículo 90.3, en virtud del cual se prevé un régimen especial para acceder a la libertad condicional a los penados que estén cumpliendo su primera condena de prisión, siempre que no supere los tres años. 
Tabla 5. Distribución de la población penitenciaria en atención a la edad

\begin{tabular}{lrrr}
\hline Edades & Hombres & Mujeres & \multicolumn{1}{c}{ Total } \\
\hline De 18 a 20 años (penados) & 305 & 12 & 317 \\
De 21 a 25 años (penados) & 4.187 & 281 & 4.488 \\
De 26 a 30 años (penados) & 7.283 & 571 & 7.954 \\
De 31 a 40 años (penados) & 16.455 & 1.401 & 17.856 \\
De 41 a 60 años (penados) & 18.518 & 1.605 & 20.123 \\
De más de 60 años (penados) & 1.852 & 136 & 1.988 \\
No consta (penados) & 5 & 0 & 5 \\
Totales & 48.705 & 4.006 & 52.711 \\
\hline
\end{tabular}

Fuente: datos del Ministerio del Interior.

Finalmente, si se analiza la edad de las personas privadas de libertad, podrá comprobarse cómo la franja de entre 41 a 60 años es la más común, tanto cuando se trata de hombres como de mujeres (penados o penadas). Esto determina que los establecimientos penitenciarios que los acogen deben estar preparados para recibir a una población penitenciaria adulta. Así, si se centra la atención en los datos existentes a 31 de diciembre de 2015, esta es la imagen etaria que presentan las prisiones españolas:

Se da la circunstancia de que, entre jóvenes y mayores de 60 años, las cifras se aproximan proporcionalmente. Este dato ha de ser analizado, porque la gran diferencia entre la delincuencia femenina y la masculina se produce en las edades centrales de la vida, mientras que, en la adolescencia, en la juventud y en la edad madura, parece que tienden proporcionalmente, si no a "equipararse», sí a acercarse de forma tendencial. Sin duda alguna, los estereotipos de género están más marcados durante esos años centrales de la vida, en las que se asumen las riendas de una familia y es la edad fértil de las mujeres.

Por otro lado, la edad en la que más diferencias existen en términos generales es el tramo en el que las mujeres asumen mayores responsabilidades familiares, cuando se encargan del cuidado de los miembros dependientes de su familia. Puede decirse, pues, que, de nuevo, hoy los roles de género las siguen teniendo controladas a ellas. En este sentido, es preciso resaltar que la privación de libertad de una mujer en esta fase de su vida le provoca una sensación de incumplimiento de sus responsabilidades que no sufren en igual medida los hombres, que no han asumido, en razón de su género, el cuidado de la familia más allá de su mantenimiento económico, del que tampoco son ajenas las mujeres. De ahí el sufrimiento añadido que representa la institución carcelaria para el género femenino.

\subsubsection{La jurisprudencia}

Pero, más específicamente, como se decía, con carácter general, los estudios estadísticos desprecian una serie de datos que solo pueden ser complementados a través de la lectura de la jurisprudencia. Basta llevar a cabo un análisis cualitativo de la misma, puesto que, de ella, se desprenden conclusiones muy interesantes desde una perspectiva de género. 
En esta línea, la primera sentencia que merece ser resaltada es la de la Audiencia Provincial de A Coruña 7/2012, de 10 de febrero (JUR/2012/97742), en la que se condena a un hombre y a una mujer —que son pareja - por un delito de tráfico de drogas. A ambos, a identidad de hecho, se les impone pena distinta, menor para la mujer, en atención al siguiente razonamiento: "para la imposición de la pena en una extensión próxima al mínimo legal a la acusada se ha atendido a su condición de madre de dos hijas menores, a la no constancia de inserción en el mercado laboral y a la convivencia con su marido consumidor de drogas». Al marido también se le atenúa la pena, pero, en este caso, en aplicación de la atenuante de drogadicción. A pesar del esfuerzo loable que realiza la Audiencia para conseguir la pena más reducida posible para ambos, hay que señalar que ni la maternidad, ni la inserción laboral, ni la convivencia con el marido toxicómano son circunstancias que añadan nada al delito de tráfico de drogas cometido y están completamente desconectadas del mismo, por lo que, en puridad de principios, debería ser una línea de interpretación jurisprudencial de la que huir.

Si se tiene en consideración que el delito que da lugar al mayor número de internamientos en las cárceles españolas de las mujeres es el del tráfico de drogas, que, en los casos más graves en atención al volumen (y la pureza) de las cantidades traficadas, tiene un carácter internacional, puede limitarse la búsqueda de jurisprudencia a las audiencias provinciales de Madrid, Barcelona y Málaga, ciudades que cuentan con los tres grandes aeropuertos españoles por donde entra gran cantidad de droga al mercado para su posterior distribución. Y, por otro lado, la Audiencia Provincial de Cádiz, ciudad por la que entra el hachís proveniente del norte de África por carretera. En todos estos casos, en la medida en que la Ley de Enjuiciamiento Criminal establece el locus commisii delicti como el determinante de la competencia procesal, el número de sentencias por delitos relacionados con el tráfico de drogas es muy elevado ${ }^{11}$.

De la lectura de la jurisprudencia, en efecto, saltan a la luz datos de interés relativo a las mujeres de nacionalidad extranjera provistas de autorización para turistas, que son detenidas en el aeropuerto por el transporte de drogas en su propio cuerpo o en su equipaje, sin haber salido siquiera de la zona internacional, o fuera del mismo, cuando, detectada la operación de tráfico por la policía, se le permite salir bajo control, a fin de descubrir a otras personas implicadas. Estas mujeres son extranjeras, pero no son inmigrantes en España y, por tanto, cuando se computa la criminalidad de las mujeres de nacionalidad extranjera, hay que tener en consideración que estos casos no deberían, en puridad de principios, computarse dentro de la criminalidad de las inmigrantes, porque no lo son (Boza, 2015: 261 y s.). Por otro lado, este hecho va a determinar que carezcan de arraigo y de domicilio en España, con lo cual van a estar más tiempo en prisión, porque todos los mecanismos que prevé la legislación penitenciaria española para alcanzar la reinserción social parten de que se trata de 
personas que vuelven a insertarse en la sociedad en la que previamente vivían, y no es este, precisamente, su caso ${ }^{12}$.

Pero si se analiza otro grupo de sentencias en las que se castigan ya a mujeres que viven en España por la realización de operaciones de tráfico de drogas a pequeña escala, salen a relucir múltiples matices de género. En este sentido, ha de tenerse en consideración que si bien el artículo 23 del Código Penal considera que el parentesco entre la víctima y el autor del delito es causa que puede agravar o atenuar la pena ${ }^{13}$, el "parentesco" del autor del delito con otras personas implicadas en los hechos es un dato irrelevante desde el punto de vista penal ${ }^{14}$, aunque tiene una relevancia innegable desde el punto de vista criminológico. Todo esto ha dado lugar a que la jurisprudencia analice con cuidado la imputación de responsabilidad criminal en estos casos, pues no puede considerarse de forma automática autoras de un delito a todas las personas que habitan en el mismo domicilio, por ejemplo. En este sentido, de la SAP de Cádiz 432/2009, de 27 de noviembre (ARP/2012/1492), parece deducirse una especie de responsabilidad de la familia o «clan familiar», aunque acaba aplicando una excusa absolutoria a la madre ${ }^{15}$. Huyendo de interpretaciones simplistas, un amplio sector de la jurisprudencia intenta poner límites a la imputación de la responsabilidad criminal. Así, la SAP de Alicante 75/2012, de 21 de marzo (JUR/2012/294764), analiza la responsabilidad criminal de la esposa de un sujeto que es condenado por tráfico de drogas y afirma que:

[...] el hecho de la ocupación en poder de su marido de una importante cantidad de droga y de los útiles anteriormente referidos en su domicilio son indicios relevantes de delito. Ello no obstante, condenado Faustino, cabe como hipótesis posible, y más favorable para la acusada que aquél se dedicara en exclusiva al tráfico de drogas.

Por lo mismo, no son pocos los casos en los que la mujer es condenada por tráfico de drogas, al intentar introducir, mediante su hijo o su marido, droga dentro de la prisión, como es el caso de la SAP de Barcelona 12/2012, de 9 de enero (JUR/2012/88078), en la que se condena a una mujer marroquíi ${ }^{16}$. En

12. Véanse, por todas: SAP Barcelona 247/2012, de 19 de abril (ARP/2012/658); SAP de Barcelona 384/2011, de 25 de mayo (JUR/2011/300633); SAP de Barcelona 165/2012, de 27 de febrero (JUR/2012/106945); SAP de Barcelona 616/2010, de 20 de julio (JUR/2010/387845); SAP de Alicante 544/2012, de 12 de noviembre (JUR/2013/55336), y SAP de Alicante 310/2011, de 28 de octubre (JUR/2011/401939).

13. Y eximir, en los casos previstos en el artículo 268.

14. A no ser que se recurra a la circunstancia atenuante analógica.

15. También puede verse la SAP 309/2008, de 26 de septiembre (ARP/2012/1199). en la que se concluye que ser esposa no es suficiente para considerar una mujer coautora de un delito de tráfico de drogas.

16. Finalmente, es condenada por el tipo básico del artículo 368, no por el agravado. Puede verse también la SAP de Barcelona 49/2011, de 1 de abril (JUR/201/402639), en un caso de una madre que intenta introducir droga en prisión a su hijo: se le impuso la pena de prisión de 9 meses, aplicando el parentesco como una circunstancia atenuante muy cualificada de forma poco ortodoxa, porque dicho parentesco ha de darse entre el sujeto activo y el pasivo, 
estos supuestos, los procesos de victimización y de criminalización del comportamiento de la mujer coinciden en el tiempo.

Finalmente, y por lo que se refiere al consumo de sustancias tóxicas y a la condición de toxicómana de la mujer traficante de drogas, no son pocas las sentencias en las que se tiene en consideración, la mayoría de las veces para apreciar la circunstancia de drogadicción prevista en el artículo 21.7, y mucho menos frecuentes las que aplican la eximente incompleta de drogadicción de los artículos 21.1 y 20.2. Lo que sí parce que llama la atención desde esta perspectiva es que se trata de mujeres de nacionalidad española que, en todos los casos, se dedican al tráfico de drogas como medio para sufragar su propia dependencia. Esto puede venir a poner de manifiesto que, si bien cuando se trata de la delincuencia de mujeres nacionales españolas, se puede afirmar que es más frecuente que sean condenadas por delitos «funcionales» a su drogadicción y la forma de prevenirlos pasa directamente por la puesta en marcha de programas de deshabituación, cuando se trata de mujeres de nacionalidad extranjera, el delito cometido no se relaciona funcionalmente con dependencia de sustancia tóxica alguna ${ }^{17}$.

Respecto a los delitos contra el patrimonio, el Balance de Criminalidad del Ministerio del Interior no distingue entre cuáles son las modalidades concretas de los cometidos por mujeres ${ }^{18}$. El dato es relevante, en la medida en que, si se observa, dentro de este listado, se incluyen figuras como el hurto, la estafa o la apropiación indebida, que no requieren el empleo de violencia o de fuerza por parte del autor, sino que más bien necesitan de su astucia, frente a los delitos de robo - con fuerza en las cosas o con violencia o intimidación en las personas-, en los que sí se requiere que se corra una cierta dosis de riesgos, pues se ha de estar en condiciones de hacer frente a la resistencia física que pueda interponer la víctima o un tercero que salga en su auxilio. Se trata, en definitiva, de atentados «violentos» contra el patrimonio. La falta del número estadístico se suple, no obstante, con la lectura de la jurisprudencia, que proporciona un número elevado de ejemplos de mujeres condenadas por delitos patrimoniales no violentos (puede verse la SAP de Asturias 61/2012, de 17 abril [JUR/2012/167149]), de mujeres condenadas como "partícipes» en el delito patrimonial violento del que es autor principal un hombre (SAP de

y el «hijo» no es precisamente el sujeto pasivo de un delito contra la «salud pública». Por todos, véase Acale Sánchez, María (2002). Salud pública y drogas tóxicas, Valencia, Tirant lo Blanch, 146 y s.

17. Puede verse la SAP de Barcelona 520/2012, de 22 de mayo (JUR/2012/263256), en la que se castiga a una mujer por la venta de una papelina de heroína, con la aplicación de la atenuante de análoga significación del artículo 21.7 en relación con la eximente incompleta del artículo 21.1: se le impuso la pena en su grado mínimo, decretándose la suspensión de la ejecución.

18. Pueden verse los datos que arroja el Informe General 2011 de Instituciones Penitenciarias (op. cit., p. 59), que, aunque distingue a la hora de realizar el cálculo del porcentaje de delitos imputados a la población reclusa extranjera, por grandes bloques —entre ellos, los delitos contra el patrimonio, distinguiendo entre estafa, hurto, robo, robo con fuerza en las cosas y robo con violencia-, no discrimina las cifras por género. 
Albacete 85/2010, de 17 de junio [JUR/2010/266691]) ${ }^{19}$ y de mujeres que, con el síndrome de abstinencia — que, sin duda alguna, debe envalentonar a cualquiera que lo sufra-, cometen delitos patrimoniales violentos (SAP de Cáceres 367/2011, de 28 de octubre [JUR/201/393604]) ${ }^{20}$.

Los datos que se desprenden de la jurisprudencia vienen, pues, a confirmar los patrones de género y la dependencia de la mujer delincuente, que no era posible de obtener con la mera lectura de la estadística.

\section{El tratamiento penitenciario de género}

\subsection{Planteamiento}

El proceso de reinserción social de estas mujeres pasa por la puesta en marcha de programas que, a la vez que las preparen para cuando alcancen la libertad, lo haga en el marco de una sociedad más igualitaria y, por ende, más justa. Por ello, en prisión no pueden desconocerse los condicionantes de género de la victimización y de la criminalidad femenina, más aún en aquellos supuestos en los que el proceso de criminalidad fue precedido por un acto de victimización, pues, de lo contrario, se estará ignorando algo que, para estas mujeres, ha ocupado - y, en muchos casos, sigue ocupando - un lugar prioritario en sus vidas. En esta línea, de poco sirve denunciar la violencia de género como la forma más brutal de discriminación femenina si, a la vez, se ofrecen programas de tratamiento de corte sexista y nada igualitarios, porque el Estado está obligado a remover los obstáculos para que las mujeres que están privadas de libertad cumplan sus penas en igualdad de condiciones que los hombres, poniendo en marcha las medidas que impidan que sea más costosa para ellas la vida en prisión y la vida que les queda después de la prisión (en atención al mandato contenido en el artículo 9.3 de la Constitución).

La sociedad en su conjunto está llamada a desempeñar un papel esencial en el proceso de criminalización y de reinserción social de estas mujeres, a las que, en muchos casos, se les reprocha, más que el hecho de haber cometido un delito, el pecado de haber delinquido, y en vez de imponerle una pena, se les impone su particular pesado castigo. Si conjugáramos el verbo "penar», en definitiva, podríamos decir que la sociedad no puede limitarse a contemplar a estas mujeres que están "penando".

El proceso de reinserción social de estas mujeres debe partir de la idea básica de que, cuando recuperen la libertad, no vuelvan a cometer ningún delito, pero también debe procurar que, cuando llegue ese momento de recuperar la libertad, no vuelvan a ser discriminadas en razón de su género y de su nacio-

19. La mujer es castigada como cooperadora necesaria, porque "contribuyó con su presencia en la intimidación, y se marchó después aprovechándose de su comportamiento para consumar la ilícita apropiación».

20. Se trata de dos mujeres politoxicómanas castigadas por robo con violencia, a las que se les aplica la circunstancia atenuante analógica del artículo 20.2, si bien se le impone pena de prisión, y no medida de seguridad. 
nalidad. En este sentido, las políticas que inciden en remarcar los estereotipos que condicionaron en muchos casos el iter criminal de estas mujeres son útiles para mantener el orden intrapenitenciario, porque domestican a un sector de la población penitenciaria que puede llegar a ser tremendamente dócil, pero no están legitimadas en el marco del objetivo esencial de la igualdad.

\section{2. ¿Visión de género o sexismo puro?}

En la actualidad, como es sabido, la Ley Orgánica 1/1979, de 26 de septiembre, General Penitenciaria, y el Reglamento que la desarrolla diseñan la ejecución de la pena privativa de libertad en términos de igualdad, tanto para hombres como para mujeres (sobre arquitectura penitenciaria para mujeres, véase Yagüe, 2012: 32 y s.), llegando al punto de haber unido los cuerpos de funcionarios de instituciones penitenciarias, pues, tras la aprobación de la Ley Orgánica 3/2007, para la igualdad efectiva de hombres y mujeres, el Real Decreto 1836/2008, de 8 de noviembre, por el que se establecen criterios para la aplicación de la integración de las extintas escalas masculinas y femeninas del Cuerpo de Ayudantes de Instituciones Penitenciarias, estableció, en su artículo 1 , que

[...] la Administración general del Estado gestionará la prestación de los servicios y actividades de vigilancia en el interior de los centros penitenciarios y centros de inserción social, de acuerdo con el principio de no discriminación por razón de sexo en el empleo público.

Tan solo quedan algunas especialidades en razón del sexo de la persona privada de libertad. En este sentido, partiendo del principio básico en materia de ejecución de esta pena de separación por sexos (artículo 8.3, 16.a de la Ley Orgánica 1/1979, de 26 de septiembre, General Penitenciaria), se establece que, en los centros de mujeres, deberá contarse con dependencias médicas dotadas del material de obstetricia necesario para el tratamiento de las internas embarazadas y de las que acaben de dar a luz y se encuentren convalecientes, así como para atender aquellos partos que, por motivos de urgencia, no puedan ser asistidos en hospitales comunes (artículo 38 de la Ley Orgánica 1/1979, de 26 de septiembre, General Penitenciaria, y 209 del Reglamento que la desarrolla). En cuanto a las sanciones disciplinarias a imponer, el artículo 43.3 establece que el aislamiento en celda no se aplicará «a las mujeres gestantes y a las mujeres hasta seis meses después de la terminación del embarazo, a las madres lactantes y a las que tuvieran hijos consigo" (en el mismo sentido, el artículo 254 del Reglamento). Más allá de estas previsiones, no existe diferenciación legal alguna.

Sin embargo, a pesar de que la Ley Orgánica 1/1979, de 26 de septiembre, General Penitenciaria haya equiparado la forma de ejecución de las penas privativas de libertad, al margen ya de las especialidades señaladas, ha de decirse que la práctica pone de manifiesto que, en muchas cárceles, no se cumple lo 
dispuesto en aquella. En este sentido, la mayor vulneración de los derechos de las mujeres presas se pone de manifiesto en el ámbito de la clasificación penitenciaria. En efecto, a pesar de que se establezca que las personas privadas de libertad penadas serán clasificadas en primero, segundo o tercer grado, ateniendo a su progresión penitenciaria (artículo 72 del Reglamento Penitenciario), y que cumplirán sus condenas separadas unas de otras en distintos establecimientos penitenciarios, como las mujeres presas son pocas, están abocadas en muchas cárceles a cumplir sus condenas todas juntas - las jóvenes con las adultas, las reincidentes con las no reincidentes, las madres con hijos con las mujeres sin hijos—, con lo que se vacía así —en razón de género— de contenido el régimen progresivo de ejecución de la pena privativa de libertad en estos casos. Puede decirse, pues, que purgan juntas sus penas por razón de género y que, en detrimento de sus «derechos penitenciarios», la cárcel es más dura para las mujeres. Todo ello puede estar contribuyendo a que su proceso de reinserción social posterior sea más costoso (Igareda, 2007: 78).

Pero aunque, como se ha señalado, el diseño de la pena privativa de libertad no distingue en razón de sexos, sí existen dos previsiones específicas en razón de género que, quizás, en el marco de un ordenamiento jurídico que cuenta con la Ley Orgánica 3/2007, de igualdad efectiva de hombres y mujeres, sería necesario que se replantearan.

La primera de ellas está contemplada en el artículo 38.2 de la Ley Orgánica 1/1979 General Penitenciaria, así como en el artículo 17 del Reglamento, que prevén la posibilidad de que las madres internas puedan tener consigo a sus hijos hasta que cumplan tres años (Yagüe, 2002: 157; Naredo, 2007: 263), en la medida en que es un derecho que solo se reconoce a las internas que tengan hijos, y no a los internos padres, parece que sigue teniéndose en consideración que es la mujer la que se encarga del cuidado de su descendencia. Ha de resaltarse que el Reglamento, en su artículo 99.3, así como en el capítulo in del título viI (artículo 68), prevé la posibilidad de que existan cárceles mixtas de cumplimiento de pena. En estos casos, cuando entren en el centro hombres y mujeres y estas tengan a su cargo menores de tres años, no habrá inconveniente para que el padre pueda estar con sus hijos, pero si se observa, a través de la madre $^{21}$ (Yagüe, 2002: 157; Naredo, 2007: 263).

En segundo lugar, ha de resaltarse la previsión contenida en el artículo 82.2 del Reglamento Penitenciario, en virtud del cual se regula una vía de acceso especial al régimen abierto restringido «en el caso de mujeres penadas clasificadas en tercer grado, cuando se acredite que existe imposibilidad de desempeñar un trabajo remunerado en el exterior, pero conste, previo informe de los servicios sociales correspondientes, que va a desempeñar efectivamente

21. En relación con el lugar de cumplimiento, el artículo 178 del Reglamento establece que las madres con hijos menores serán destinadas a las unidades de madres, "que contarán con local habilitado para guardería infantil y estarán separadas arquitectónicamente del resto de los departamentos, a fin de facilitar las especificidades regimentales, médico-sanitarias y de salidas que la presencia de los menores en el centro hiciesen necesarias» (art. 17.5). 
las labores de trabajo doméstico en su domicilio familiar». Como se observa, se trata de una disposición que es aplicable para conceder el régimen abierto a las mujeres que ya estén clasificadas en tercer grado, aunque sin duda alguna puede estar influyendo también para la clasificación en el tercer grado propiamente dicho. A todas luces, en un ordenamiento jurídico que cuenta con una ley como la Ley Orgánica 3/2007, para la igualdad efectiva entre hombres y mujeres que consagra, en su artículo 4, que "la igualdad de trato y de oportunidades entre mujeres y hombres es un principio informador del ordenamiento jurídico y, como tal, se integrará y observará en la interpretación y aplicación de las normas jurídicas», parece que la previsión contenida en el artículo 82.2 del Reglamento no tiene lugar alguno y que ha de ser eliminada del grueso que conforma la legislación penitenciaria española.

En ambos casos, no se hace más que incidir en la tradicional distribución de roles, en virtud de la cual, la mujer ha tenido atribuidas las responsabilidades sobre el cuidado de los hijos y las tareas domésticas.

Con lo cual, si, como se decía al inicio, empiezan a salir a flote datos que resaltan la vinculación entre victimización y criminalidad (Herrera, 2012: 302), siendo así que muchos de los delitos que tienen como víctima a una mujer el autor las agrede por el hecho de ser tales, con lo que el carácter discriminador de su acción queda resaltado, al final, cuando esas mismas mujeres entran en prisión a cumplir la pena impuesta, Instituciones Penitenciarias les responde reproduciendo los patrones machistas de comportamiento.

Es necesario constatar que, en el programa de acciones para la igualdad entre mujeres y hombres en el ámbito penitenciario, se ponía en valor como una de las medidas que debía seguir la institución para incorporar el género a la ejecución de la pena privativa de libertad profundizar

[...] en esta línea y atendiendo a la escasa peligrosidad social de las mujeres y de acuerdo con los principios de la mínima intervención del derecho, se pretenden impulsar cambios legales con medidas de atenuación, suspensión o sustitución de las penas de prisión para mujeres embarazadas y las que tengan a su cargo hijos no emancipados o personas mayores o dependientes (con aplicación de estas medidas para los hombres que sobrelleven efectivamente cargas familiares similares) ${ }^{22}$.

Pero se insiste en que, aunque el objetivo es loable, hay otros medios para alcanzar el resultado de beneficiar a esas mujeres; por ejemplo: centrar el debate en una disminución generalizada del protagonismo que hoy tiene la pena privativa de libertad dentro del Código Penal, con independencia ya del sexo del sujeto activo, ya sea porque se recurra a penas alternativas de otra naturaleza (o de idéntica naturaleza pero ejecutadas de forma discontinua, como los arrestos de fin de semana), porque se reduzca la imposición de las penas privativas de libertad para los delitos patrimoniales y los relacionados con la salud pública,

22. Secretaría General de Instituciones Penitenciarias, Programa de acciones para la igualdad entre mujeres y hombres en el ámbito penitenciario, op. cit., p. 37. 
que son los que mantienen en prisión hoy a la mayor parte de la población penitenciaria - masculina y femenina - o porque se prevean mecanismos de sustitución de las penas cortas privativas de libertad. Y, en ese marco, será bienvenido el debate en torno a la necesidad de incorporar una perspectiva de género no discriminatoria ni reproductora de los patrones machistas de comportamiento, que, por una parte, fomente la formación de las mujeres en profesiones no habituales para ellas y, a la vez, haga recaer sobre los hombres responsabilidades familiares, subrayando el hecho de que el cuidado de los hijos, por ejemplo, no es solo competencia de sus madres, sino también de sus padres, apuestas que están en sintonía todas ellas con el espíritu y con la letra de la Ley Orgánica 3/2007, para la igualdad efectiva de hombres y mujeres.

A ello ha de añadirse, por otro lado, que, paradójicamente, las mujeres que llegan finalmente a los establecimientos penitenciarios reciben, por parte de la institución, una formación que tiende a reproducir los patrones machistas de comportamiento, en la medida en que las actividades ocupacionales que se les proporcionan tienen en consideración precisamente aquellas labores en las que tradicionalmente se han ocupado. Así, es común encontrarse en un establecimiento tipo, donde, en un módulo de hombres, se llevan a cabo unos talleres —albañilería, jardinería, electrónica, etc.— distintos a los que se llevan a cabo en el de mujeres — moda, cine, lectura, costura, macramé, peluquería, etc. $-{ }^{23}$. No puede ser negada la bondad de Instituciones Penitenciarias en ese punto; ahora bien, lo que ha de plantearse es la eficacia de medidas como estas que perpetúan a cada cual en los papeles en que el patriarcado ha situado a hombres y a mujeres ${ }^{24}$, y debería tenerse en cuenta la posibilidad de sacar partido a otro tipo de habilidades. En esta línea, Viedma Rojas y Frutos Balibrea han constatado cómo, en el ámbito del trabajo penitenciario, se reproducen las limitaciones sexistas de siempre, lo que ha de ponerse en relación con el tipo de trabajo que desarrollan dentro de la prisión, que está menos cualificado que el de los hombres y peor retribuido económicamente, lo que les lleva a concluir que:

[...] la idea que se puede extraer de estos resultados es que las mujeres están más ocupadas que los varones, pero lo están en las peores tareas. La segunda idea es que su ocupación se centra mayoritariamente en los cuidados (cocina, lavandería) y limpieza. (Viedma y Frutos, 2012: 100)

23. No puede dejar de señalarse que la crisis económica ha determinado que muchos de los talleres y de las terapias ocupacionales que se estaban llevando a cabo han sido paralizados.

24. Véase, por ejemplo: http://www.rtve.es/noticias/20110215/festival-ellas-crean-lleva-cinemusica-moda-hasta-carceles-mujeres/407221.shtml. La Asociación de Derechos Humanos de Extremadura, por ejemplo, concluye que las mujeres «en las prisiones extremeñas se ven marginadas respecto a las actividades laborales, deportivas, recreativas, culturales y formativas, debido a que la población es mayoritariamente masculina y no disponen de espacios específicos para mujeres (los hombres salen de sus módulos para hacer actividades; las mujeres, no). Además, su situación económica es peor, ya que suelen tener hijos/as a su cargo" (http://centroderechoshumanos.com/acerca-de/adhex). 
De ahí que deba puntualizarse la afirmación que realiza Instituciones Penitenciarias en su Programa de acciones para la igualdad entre mujeres y hombres en el ámbito penitenciario, cuando afirma que las mujeres «aunque acceden a algunas actividades profesionales de alta inestabilidad en nuestro mercado de trabajo, como confección y manipulados, apenas se incorpora a los talleres y actividades considerados tradicionalmente masculinos ${ }^{25}$, pues quizás la cuestión es previa, es decir, si se les ofrece y si se potencia que las mujeres sigan esos cursos.

La crítica que se hace a la distribución por sexos del trabajo dentro de la prisión cobra aún mayor relevancia en forma de cumplimiento de la pena privativa de libertad en las que no exista separación por sexos, como sería en los centros mixtos de cumplimento del artículo 99.2 del Reglamento Penitenciario o en los grupos en comunidad terapéutica del artículo 115 del mismo cuerpo legal.

Si a ello se le une, como se decía anteriormente, que, según estudios realizados por Instituciones Penitenciarias, el número de mujeres privadas de libertad que han sufrido o están sufriendo violencia a manos de sus maridos o de sus compañeros sentimentales es muy elevado, a fin de dotar a estas mujeres de instrumentos y estrategias para saber afrontar y poder salir de las situaciones de maltrato, podrá concluirse que puede resultar contradictorio para ellas estar recibiendo en prisión formación para que puedan salir de una situación de violencia, cuando esa misma formación está basada en los mismos patrones de comportamiento machista que las victimiza.

Todo ello puede estar contribuyendo a que su proceso de reinserción social sea más artificial aún si cabe que el de los hombres (Igareda, 2007: 78).

Finalmente, de la situación en la que se encuentra esa población penitenciaria es necesario analizar los grados de tratamiento en los que está clasificada.

Sobre la base de dichos datos, puede afirmarse que el segundo grado es el que mayor número de personas privadas de libertad soporta. Quienes se encuentran en situación de preventivos no son objeto de clasificación, si bien son reconducidos a establecimientos penitenciarios (o módulos, en las prisiones tipo) de segundo grado, que se convierte así en el más extendido — hombres y mujeres_- Las mujeres clasificadas en primer grado son las mínimas.

Ahora bien, si se tiene en consideración, por un lado, el número de mujeres clasificadas en cada uno de los grados y, por otro, el número de establecimientos penitenciarios por comunidades autónomas, se comprenderá que, si bien los hombres tienen garantizado su derecho a la separación penitenciaria y a cumplir sus penas con las cautelas señaladas, el número de establecimientos penitenciarios y su distribución geográfica puede estar condicionando la ejecución cuando de mujeres se trate (Igareda: 2007, 95). Por tanto, a pesar de que la Ley Orgánica 1/1979, de 26 de septiembre, General Penitenciaria, haya equiparado la forma de ejecución de las penas privativas de libertad, al

25. Secretaría General de Instituciones Penitenciarias, Programa de acciones para la igualdad entre mujeres y hombres en el ámbito penitenciario, op. cit., p. 26. 
Tabla 6. Distribución de la población penitenciaria por grados de tratamiento

\begin{tabular}{|c|c|c|c|c|c|c|c|c|c|c|c|c|c|c|}
\hline \multirow[b]{2}{*}{ Grados } & \multicolumn{2}{|c|}{2009} & \multicolumn{2}{|c|}{2010} & \multicolumn{2}{|c|}{2011} & \multicolumn{2}{|c|}{2012} & \multicolumn{2}{|c|}{2013} & \multicolumn{2}{|c|}{2014} & \multicolumn{2}{|c|}{2015} \\
\hline & $\mathrm{H}$ & M & $\mathrm{H}$ & M & $\mathrm{H}$ & M & $\mathrm{H}$ & $M$ & $\mathrm{H}$ & $M$ & $\mathrm{H}$ & $M$ & $\mathrm{H}$ & $M$ \\
\hline imero & & 77 & 3 & & 27 & 1 & 1.012 & 88 & 060 & 78 & 1.024 & 79 & 972 & \\
\hline gundo & 38.868 & 3.738 & 39.460 & 2.792 & 38.068 & 2.433 & 38.088 & 2.583 & 36.662 & 2.711 & 38.494 & 2.747 & 37.049 & 2.656 \\
\hline ercero & 8.444 & 1.174 & 8.520 & 1.211 & 8.534 & 1.167 & 7.992 & 1.091 & 7.683 & 1.032 & 7.520 & 967 & 7.163 & 968 \\
\hline , & 6.613 & 634 & 5.790 & 380 & 5.842 & 398 & 4.889 & 366 & 4.538 & 339 & 3.960 & 323 & 3.521 & 30 \\
\hline
\end{tabular}

Fuente: datos del Ministerio del Interior

margen ya de las especialidades señaladas, ha de decirse que la práctica pone de manifiesto que, en muchas cárceles, no se cumple lo dispuesto en aquella, porque las mujeres están abocadas a cumplir sus condenas todas juntas - las jóvenes con las adultas, las reincidentes con las no reincidentes, las madres con hijos con las mujeres sin hijos, etc.-, con lo que se vacía —en razón de género-, como se decía anteriormente, de contenido el régimen progresivo de ejecución de la pena privativa de libertad en estos casos, puesto que purgan juntas sus penas por razón de género.

Finalmente, de los datos que se desprenden del cuadro anterior, se aprecia que el número de mujeres clasificadas en tercer grado es superior al número de hombres - proporcionalmente, no en número reales. Así, a partir de los datos correspondientes a 31 de diciembre de 2015, vemos el desglose por sexos (tabla 7).

En efecto, si bien, cuando se analizan los porcentajes de primeros y segundos grados, la distribución de la población penitenciaria por sexos es casi idéntica, en terceros grados la equivalencia se rompe, de modo que el número de hombres que lo disfrutan disminuye al $88 \%$ y el de mujeres sube al $11,9 \%$ en comparación con las cifras anteriores.

En este sentido, aunque, a priori, la Ley Orgánica 1/1979, de 26 de septiembre, General Penitenciaria, no distinga en atención al sexo la ejecución

Tabla 7. Distribución por sexos y grado de tratamiento

\begin{tabular}{lc}
\hline 7.1. primer grado & \\
\hline Total primer grado & 1.054 \\
Hombres & $972(92,2 \%)$ \\
Mujeres & $82(7,7 \%)$ \\
\hline 7.2. segundo grado & \\
\hline Total segundo grado & 39.705 \\
Hombres & $37.049(93,3 \%)$ \\
Mujeres & $2.656(6,6 \%)$ \\
\hline 7.3. tercer grado & \\
\hline Total tercer grado & 8.131 \\
Hombres & $7.163(88,09 \%)$ \\
Mujeres & $968(11,9 \%)$
\end{tabular}


de la pena privativa de libertad, hay que resaltar la posibilidad que establece el artículo 82.2 del Reglamento Penitenciario de que las mujeres accedan al régimen abierto a través de una vía especialmente prevista para ellas:

[...] cuando se acredite que existe imposibilidad de desempeñar un trabajo remunerado en el exterior, pero conste, previo informe de los servicios sociales correspondientes, que va a desempeñar efectivamente las labores de trabajo doméstico en su domicilio familiar.

Como se señalaba anteriormente, quizás un ordenamiento jurídico que cuenta con una ley orgánica de igualdad debería replantearse la reproducción de los patrones machistas de comportamiento, que, en muchos casos, son los mismos que están detrás de los delitos cometidos por estas mujeres, puesto que la reinserción social pasa, en primer lugar, por intentar que estas personas no vuelvan a cometer un delito en el futuro, pero, simultáneamente, porque no vuelvan a soportar las situaciones discriminantes que fueron caldo de cultivo de su propia forma de pensar y de creer en las relaciones humanas.

En definitiva: mujer adulta, con necesidades económicas, de bajo nivel de estudios, que tiene que hacer frente a obligaciones familiares (ya sea el cuidado de sus hijos, de sus progenitores o de su pareja, que muchas veces está en prisión a la vez que ella por la misma causa) y de carácter no violento. Este es, pues, el perfil de la mujer delincuente, marcado, sin duda alguna, por razón de su género y también de su nacionalidad, que, al margen del delito cometido, parece que marca más fuertemente la pena y la forma en la que cumplen la pena impuesta en la sentencia.

Ha de criticarse el hecho de que la estadística penitenciaria guarde silencio en torno a dos cuestiones elementales: la primera de ellas, la relativa al número de personas que se someten en prisión a tratamiento penitenciario, y la segunda, que se guarda también silencio en torno a la reincidencia penitenciaria, esto es, acerca de personas que, habiendo pasado por una prisión con anterioridad, vuelven a ser encarceladas. $Y$ estas son las dos cuestiones esenciales en las que debería haberse centrado, pues, precisamente, son las que ponen de manifiesto la reeducación y la reinserción social de los sentenciados a penas y a medidas penales privativas de libertad, según establece el artículo 1 de la Ley Orgánica $1 / 1979$, de 26 de septiembre, General Penitenciaria, y es que parece que ambas cuestiones están directamente relacionadas: a mayor tratamiento, menor reincidencia penitenciaria (Foucault, 2009: 270). Si estos datos, que son los esenciales, no tienen reflejo en los que se hacen públicos, es que Instituciones Penitenciarias parece que se resigna a cumplir meramente con la función secundaria - de retención y custodia de los detenidos, presos y penados, sin comprometerse a nada más, siendo así que el delito concreto cometido debería determinar la puesta en marcha de programas específicos de tratamiento, sobre los que se volverá posteriormente.

Incidir en estos programas sería una forma de hacer frente a la reincidencia, sin necesidad de construir «cárceles» morales posteriores para quienes cometan 
esos delitos tan "graves» para la opinión pública. Además, se trataría de una alternativa que se presenta como eficaz, por lo que los esfuerzos no serían gratuitos. Ello determinaría que, a día de hoy, el presupuesto económico del que dispone Instituciones Penitenciarias no tendría que estar «encadenado» a la construcción de más prisiones, todas ellas iguales a las otras — "cárceles tipo»—, que, además, terminan por uniformar el tratamiento que, en su caso, reciben los internos que en ellos habitan. Si se actuara de manera distinta, se abrirían las posibilidades a la puesta en marcha de alternativas a la prisión.

\section{Victimización secundaria}

Pues bien, a día de hoy, y después de un largo proceso de concienciación social sobre la gravedad de la violencia de género en todo el mundo, la mayor parte de los países de nuestro entorno cultural han ido aprobando instrumentos legales para prevenir la victimización primaria de las mujeres por el mero hecho de serlo. Pero tampoco se desconoce ya el peligro de revictimización que sufren ellas desde el momento en que entran en contacto con los operadores jurídicos. En esta línea, hay que subrayar los esfuerzos realizados en el seno de la Unión Europea ${ }^{26}$ para prevenirla. En concreto, la Directiva sobre las víctimas de 2012 pone el acento no ya en la prevención de la victimización primaria, sino en la prevención de esa victimización secundaria (los artículos 9.3.b hablan de la victimización secundaria o reiterada; el artículo 22 resalta sus necesidades de especial protección, y el 26 , los efectos de remarcar la necesidad de que se produzca una cooperación y una coordinación de los servicios).

En efecto, al daño directo que genera el hecho traumático del delito para la víctima (victimización primaria), es fácil que se le añadan otros perjuicios de carácter indirecto (victimización secundaria). Como ha puesto de relieve la historia del Derecho Penal español, en estos casos, no es infrecuente que el sistema se vuelva en contra de los intereses de la propia víctima, revictimizándola, al rebuscar — indagando — en su intimidad, datos que pongan de manifiesto un comportamiento «desordenado» que hubiera servido como acicate para "provocar» la agresión (léase más extensamente sobre dicho tema en Acale, 2006: 26 y s.), justificando judicialmente lo que se rechaza de plano en el ámbito de la teoría.

Entre dichos daños, se encuentran los que causan las reacciones sociales que se producen cuando se conoce el fenómeno, pues no es difícil encontrar actitudes que se olviden del hecho principal —el atentado contra los bienes

26. Decisión Marco EU-wide protection for victims of crime: Agreement on the European Protection Order, de 23 de septiembre de 2011, cuya finalidad es garantizar también a las víctimas su derecho fundamental a la libre circulación por el territorio de la Unión, llevándose consigo la orden de protección que en cualquier estado se haya adoptado. Recientemente, ha visto la luz la Directiva 2012/29/UE, del Parlamento Europeo y del Consejo, de 25 de octubre de 2012, por la que se establecen normas mínimas sobre los derechos, el apoyo y la protección de las víctimas de los delitos, y por la que se sustituye la Decisión Marco 2001/220/JAI del Consejo. DOUE, 14.11.2012. 
jurídicos de los que es titular la mujer-y se centren en el comportamiento de la víctima que los provocó, precipitándolo. De ahí que se la culpabilice de lo sucedido y de ahí también que la superación del daño por parte de la víctima no sea igual en todos los casos, sino que dependa de las posibilidades que tenga cada una de ellas de superar el episodio violento con todas sus consecuencias.

Tampoco colabora en el proceso de reinserción social de la víctima el tratamiento policial si, al daño que ha causado el hecho principal, se le añaden, por ejemplo, actitudes «paternalistas» por parte de los agentes que reciben a la víctima cuando esta va a interponer la denuncia. De ahí que sea tan importante la actuación policial, que puede determinar que la víctima se sienta protegida, segura, y que, por tanto, se contrarreste socialmente el sentimiento de inseguridad que acompaña a cualquier persona que ha pasado por el trauma de padecer un delito.

Por otro lado, la instrucción del procedimiento va a provocar que los hechos pertenecientes a la vida privada de la víctima sean conocidos por más gente, con lo que se amplifica el daño que sufre su intimidad en muchos casos, pues el hecho de que se vaya ampliando el número de personas que accede a la misma perpetúa el daño y lo amplía (Villacampa y Alonso, 2006: 345).

En ocasiones, además, esos hechos llegan a los medios de comunicación, no ya solo porque se haga pública la denuncia, sino también porque, a día de hoy, el medio utilizado para difundir esas imágenes las hace llegar a aquellos que son los que deciden convertirlas o no en noticias. Y cuando esto ocurre, la agresión a la intimidad ya no tiene freno, porque es imparable y no hay forma de reparar el daño causado. En muchos casos, los perjuicios que provoca la victimización secundaria son superiores a los causados por el propio proceso de victimización primaria (Tamarit, 2006: 32).

Todos estos daños colaterales que sufre la víctima como consecuencia del proceso de victimización primaria son imperdonables, pues pueden ser perfectamente evitados formando a los profesionales que tienen que trabajar en estos temas. Desde postulados victimológicos, pudiera decirse que la sociedad es testigo del daño que el delito ha causado a la víctima y en sus manos está hacer todo lo posible por reducir dicho daño, no por ampliarlo.

\section{Conclusiones}

El estudio de la criminalidad femenina pone de manifiesto que el género es un factor que determina que las mujeres delincan menos y que, correlativamente, vayan menos a prisión. Esta afirmación no se hace con la pretensión de que, una vez se elimine la discriminación, las mujeres delincan más, pues se trataría de un estudio que, si bien perseguiría el respeto a la igualdad y la eliminación de las causas de discriminación, perseguiría simultáneamente un aumento de la criminalidad.

Con el trabajo realizado, se ha pretendido fundamentalmente analizar la criminalidad femenina, diseccionándola y subrayando cómo la discriminación históricamente sufrida por las mujeres hace que su número sea inferior 
a la criminalidad masculina, y además pueden estar justificándose por razón de género sus preferencias criminales. Es cierto que, si no existieran esos controles informales previos que hacen que las mujeres delincan menos, habría más delincuencia femenina. Sin embargo, nuestro trabajo no aspira a que las mujeres delincan más, sino que esperamos que, comprendiendo esta criminalidad, se pueda explicar y reducir todavía más el número de delitos que cometen ellas.

Ahora bien, al margen ya de las conclusiones concretas que se extraigan, el estudio realizado ha servido para poner de relieve que una forma de reducir la criminalidad es a través de los controles sociales previos al Derecho Penal, que deberían incidir en la población con igual fuerza, sean hombres o sean mujeres. Así, solo una educación en valores, en igualdad, en resolución consensuada y pacífica de conflictos puede determinar que los hombres y las mujeres delincan también menos. La prevención de la criminalidad que aquí se persigue es una prevención que incida en las necesidades que presenten hombres y mujeres. Es una prevención respetuosa con los derechos humanos y, sobre todo, es una prevención que parte de que tanto hombres como mujeres tienen los mismos derechos y merecen una respuesta específica cuando cometen delitos.

Por tanto, creyéndonos que llevábamos a cabo un trabajo sobre criminalidad femenina, al final hemos llevado a cabo un trabajo sobre prevención de la criminalidad.

La cárcel, finalmente, se limita a domesticar a su población y, sin duda alguna, su objetivo es más fácil de alcanzar con las presas que con los presos. Por otra parte, la cárcel despersonaliza más a ellas que a ellos, con lo que se enfrentan, por razón de género, a un proceso que, en el mejor de los casos, es de reinserción social «enlatada» o «estándar». Por todo ello, el cumplimiento de una pena privativa de libertad es más costosa para las mujeres que para los hombres condenados.

En definitiva, la sociedad puede pedir legítimamente a las mujeres delincuentes que eliminen la violencia de sus vidas, pero solo si somos capaces de eliminar como sociedad la violencia de género que toleramos que soporten ellas. Si no lo hacemos, la delincuencia femenina no pasará de ser una forma equivocada e inconsciente de autodefensa.

\section{Referencias bibliográficas}

Acale Sánchez, María (2002). Salud pública y drogas tóxicas. Valencia: Tirant lo Blanch.

- (2006). La discriminación hacia la mujer por razón de género en el Código penal. Madrid: Reus.

- (2011). «Mujeres, crímenes y castigos». Hachetetepé, 2, 13-32. Monográfico "Cárceles, Educación y Medios de Comunicación».

Aguilera Reija, Marga (2005). «Situación jurídica de las extranjeras presas». En: Martín Palomo, María Teresa; Miranda López, María Jesús y Vega Solís, Cristina (eds.). Delitos y fronteras: Mujeres extranjeras en prisión. Madrid: Instituto de Investigaciones Feministas. Universidad Complutense de Madrid. 
Almeda Samaranch, Elisabet (2007). «Ejecución penal y mujer en España: Olvido, castigo y domesticidad». En: Almeda Samaranch, Elisabet y Bodelón GonzáLEZ, Encarna (eds.). Mujer y castigo: Un enfoque socio-jurídico y de género. Oñati: Instituto Internacional de Sociología Jurídica de Oñati; Madrid: Dykinson.

Bodelón GonzÁlez, Encarna (2007). «Mujer inmigrante y sistema penal en España: La construcción de la desigualdad de género en el sistema penal». En: Almeda Samaranch, Elisabet y Bodelón González, Encarna (eds.). Mujeres y castigo: Un enfoque socio-jurídico y de género. Oñati: Instituto Internacional de Sociología Jurídica de Oñati; Madrid: Dykinson.

Boza Martínez, Diego (2015). «Perspectivas postpenitenciarias de las personas privadas de libertad de nacionalidad extranjera: Entre la expulsión y el arraigo». En: Acale Sánchez, María y Gómez López, Rosario (coords.). Derecho penal, género y nacionalidad. Granada: Comares.

Dorado, María Cristina (2005). "Desventajas del castigo penal "exclusivo" a las colombianas, mensajeras de drogas en Europa». En: Martín Palomo, M. Teresa; Miranda López, M. Jesús y Vega Solís, Cristina (eds.). Delitos y fronteras: Mujeres extranjeras en prisión. Madrid: Instituto de Investigaciones Feministas. Universidad Complutense de Madrid.

Foucault, Michel (2009). Vigilar y castigar: Nacimiento de la prisión. Madrid: Siglo XXI.

Herrera Moreno, Myriam (2012). «Discursos criminológicos sobre la mujer infractora y su prisionalización». En: Mapelli Caffarena, Borja; Sordi Stock, Bárbara; Agudo Correa, Teresa; Herrera Moreno, Myriam y Gutiérrez Romero, Francisco Manuel. Mujeres en las cárceles de Andalucía. Madrid: Dykinson.

Igareda, Noelia (2007). «Mujeres en prisión». En: Cerezo Domínguez, Ana Isabel y García España, Elisa (coords.). La prisión en España: Una perspectiva criminológica. Granada: Comares.

Larrauri Pijoan, Elena (1994). "Control informal: Las penas de las mujeres». En: Larrauri Pijoan, Elena (comp.). Mujeres, Derecho Penal y criminología. Madrid: Siglo Veintiuno de España Editores.

Mestre i Mestre, Ruth (2005). «Estrategias jurídicas de las mujeres migrantes». En: Martín Palomo, M. Teresa; Miranda López, M. Jesús y Vega Solís, Cristina (eds.). Delitos y fronteras: Mujeres extranjeras en prisión. Madrid: Instituto de Investigaciones Feministas. Universidad Complutense de Madrid.

Naredo Molero, María (2005). «QQué nos enseñan las nuevas reclusas?: La criminalización de la pobreza desde la situación de las reclusas extranjeras y gitanas». En: Martín Palomo, M. Teresa; Miranda López, M. Jesús y Vega Solís, Cristina (eds.). Delitos y fronteras: Mujeres extranjeras en prisión. Madrid: Instituto de Investigaciones Feministas. Universidad Complutense de Madrid.

- (2007). «Reclusas con hijos/as en la cárcel». En: Almeda SAMARANCH, Elisabet y BodeLÓN GONZÁLEZ, Encarna (eds.). Mujeres y castigo: Un enfoque socio-jurídico y de género. Oñati: Instituto Internacional de Sociología Jurídica de Oñati; Madrid: Dykinson.

Tamarit Sumalla, Josep Maria (2006). «La victimología: Cuestiones conceptuales y metodológicas». En: Baca Baldomero, Enrique; Echeburúa Odriozola, Enrique y Tamarit Sumalla, Josep Maria. Manual de victimología. Valencia: Tirant lo Blanch.

Viedma Rojas, Antonio y Frutos Ballibrea, Lola (2012). «El trabajo en prisión: Observando las desigualdades de género». En: VAL Cid, Consuelo del y Viedma Rojas, Antonio (eds.). Condenadas a la desigualdad: Sistema de indicadores de discriminación penitenciaria. Barcelona: Icaria. 
Villacampa Estiarte, Carolina y Alonso Rimo, Alberto (2006). «La victima en el sistema de justicia penal iI». En: Baca Baldomero, Enrique; Echeburúa Odriozola, Enrique y Tamarit Sumalla, Josep Maria. Manual de victimología. Valencia: Tirant lo Blanch.

YAGÜE Olmos, Concepción (2002). «Mujer: delito y prisión: Un enfoque diferencial sobre la delincuencia femenina». Revista de Estudios Penitenciarios, 249.

- (2012). «Políticas de género y prisión en España». En: VAL Cid, Consuelo del y Viedma Rojas, Antonio (eds.). Condenadas a la desigualdad: Sistema de indicadores de discriminación penitenciaria. Barcelona: Icaria. 
